\title{
Hematological Changes Associated with Amoxicillin, Paracetamol and Their Combinations on Rabbits
}

\author{
Noor S. Abu Ebtehan and Yasser EL-Nahhal* \\ Faculty of Science, The Islamic University-Gaza, Palestine \\ *Corresponding author: Professor Dr Yasser El-Nahhal, Faculty of Science, The Islamic University-Gaza, Palestine; Tel: 00970599634708; E-mail: y_el_nahhal@hotmail.com
}

Received: November 05, 2021; Accepted: November 20, 2021; Published: November 29, 2021

\begin{abstract}
Extensive use or misuse of antibiotic and analgesic may lead to hematological changes. This study characterized the hematological changes associated with chronic gavage of Amoxicillin and Paracetamol in rabbits.

Amoxicillin, Paracetamol and their combination were dissolved in distilled water and given a rate of $(0 \mathrm{mg} / \mathrm{kg}),(8 \mathrm{mg} / \mathrm{kg}),(24 \mathrm{mg} / \mathrm{kg}) \mathrm{and}(4 \mathrm{mg} / \mathrm{kg}+12$ $\mathrm{mg} / \mathrm{kg}$ ) to four groups of rabbits (control, amoxicillin, paracetamol and mixture group) respectively for 2 weeks period followed by 6 weeks relaxation period. Then rabbits were authenticated and sacrificed, blood samples were collected in EDTA-containing tubes and analyzed for complete blood counts using the standard blood analysis method.

Results showed significant increase in white blood cell (WBC) count only in paracetamol treatment. Furthermore, significant increases in hemoglobin (HGB), hematocrit (HCT) were observed in all treatments, whereas platelet (PLT) levels significantly increased in amoxicillin and paracetamol treatments and reduced in mixture treatment. In conclusion, the tested compounds significantly changed blood parameters suggesting potential hematotoxicity due to use of amoxicillin, paracetamol or their combination.
\end{abstract}

Keywords: Amoxicillin, Blood parameters hematotoxicity, Paracetamol

\section{Introduction}

Misuse of amoxicillin (an antibiotic) and paracetamol (an analgesic) may become one of the most difficult problems facing the health sector, which must have a quick and effective solution.

Antibiotic are specific chemicals that kill, slow or stop bacterial growth, they are commonly used by physicians to treat bacterial infections. Amoxicillin was first produced in UK in 1970 and used as antibacterial infections for gram positive bacteria [1]. It has a wide spread application for medical treatments [2]. It may cause liver injury $[3,4]$, health risks due to its side effect to many organisms including fish $[5,6]$.

Paracetamol/acetaminophen is one of the most widely used analgesics, clinical studies indicated many side effects [6]. So far, paracetamol or its metabolites may cause severe hepatic failure [7-9], acute live injury and cell death $[10,11]$, inhibition of excessive amount of $\mathrm{N}$-acetyl-p-benzoquinone imine formation [12], binding quinone reductase 2 in the kidney and liver [13] kidney damage [14] and inhibition of mitochondrial respiration [15].

Hematological changes associated with amoxicillin, paracetamol or their combinations among human beings are not fully understood, a gap of information is still missing. The authors designed this study to measure the hematological changes associated with use of amoxicillin, paracetamol and their mixture on rabbits. Rabbits were chosen as experimental animals because they are big enough, and have similar physiology to human beings [16].

\section{Amoxicillin}

Amoxicillin is a $(2 \mathrm{~S}, 5 \mathrm{R}, 6 \mathrm{R})-6-[[(2 \mathrm{R})-2-$ Amino-2-(4hydroxyphenyl)acetyl]amino]-3,3-dimethyl-7oxo-4-thia-1-azabicyclo[3.2.0] heptane-2-carboxylic acid, semi-synthetic, acid stable drug belongs to a class of antibiotics called the Penicillins (B-lactam antibiotics)

\section{Materials and Methods}

\section{Chemicals}

Amoxicillin and Paracetamol (purity 99\%) were obtained from Middle East Pharmaceutical and cosmetics laboratories Co .LTD. All other chemicals used in the experiment were purchased from standard commercial suppliers.

\section{Experimental Animals}

Adult male rabbits were purchased from locally certified farms. They were housed in a suitable room equipped with air conditioning according to US-EPA 2004 for a period of two weeks initially to acclimate to insure a stable experimental condition. The rabbits were properly maintained according to the principles and guidelines issued by the Ministry of Agriculture in Gaza And US-EPA2004 for animal care, rabbits were individually placed in appropriate steel cages at $22-26^{\circ} \mathrm{C}, 40-70 \%$ humidity and a clean environment with a light $/ 12$ hour cycle. A suitable diet of balanced feed and clean water has been provided for the duration of the total experiment. 


\section{Preparation of Amoxicillin and Paracetamol Solution}

One gram (1000 mg) of Amoxicillin was dissolved in $100 \mathrm{ml}$ of distilled water and $1000 \mathrm{mg}$ of Paracetamol was dissolved in $100 \mathrm{ml}$ of distilled water under magnetic steering to ensure complete solubility of drugs. This was visualized by clean solution of water.

\section{Experimental Design}

Rabbits were randomly subdivided into four groups five rabbits each group, and monitored during 10 weeks, study period, (2 weeks of acclimatization +2 weeks of treatment +6 weeks without treatment). After acclimatization period, rabbits received the following treatments:

Group 1: Each rabbit received by oral administration amoxicillin at a rate of $8 \mathrm{mg} / \mathrm{kg}$ BW for 14 days; Group 2: Each rabbit received by oral administration paracetamol dose at a rate of $24 \mathrm{mg} / \mathrm{kg}$ BW for 14 days; Group 3: Each rabbit received by oral administration a mixture of Amoxicillin and paracetamol at a rate of $4 \mathrm{mg} / \mathrm{kg} \mathrm{BW}+12 \mathrm{mg} / \mathrm{kg}$ BW for 14 days; and Group 4: control group, each rabbit received by oral administration $1 \mathrm{ml}$ distilled water/rabbit for 14 day. Photo 1 shows the gavage process of the tested compounds.

\section{Collection of Blood Samples}

At the end of the experimental period (10 weeks) rabbits were authenticated to for blood sample collections via cardiac puncture into sterile tubes containing EDTA to prevent blood clotting, then analyzed for $\mathrm{CBC}$ using standard method and previously described [17].

\section{Statistical Analysis}

Average and standard deviation were calculated. Analysis of Variances (ANOVA) was employed to detect significant differences among treatments at p-value 0.05. p-value $\leq 0.05$ indicates significant differences among treatments whereas values $>0.05$ are not significant.

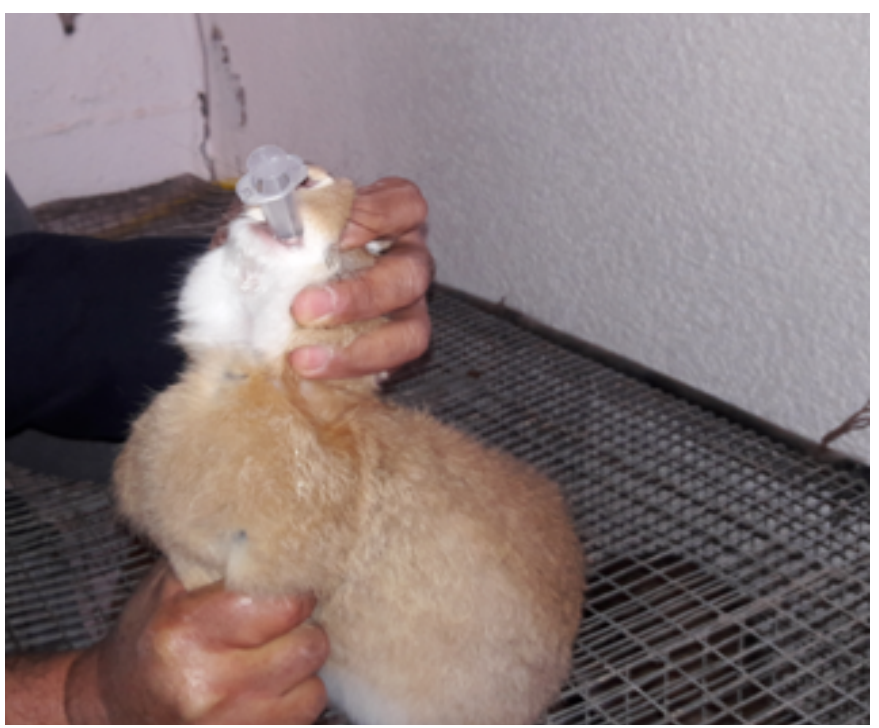

Photo 1: Oral administration of the tested compounds on rabbits

\section{Results}

\section{Effects on the Blood}

Effects of the tested compounds on white blood cells (WBC) are shown in Figure 1.

It can be seen that concentration of WBC was increased in the treated rabbits above that of the control group. Statistical analysis detected significant differences only in paracetamol treatment.

Effects on blood lymph (LYM) are shown in Figure 2.

Similarly, to the effects on WBC (Figure 2) increased levels of LYM were observed in rabbits treated with the tested compounds but statistical analysis did not detect significant differences among treatments.<smiles>CC1(C)S[C@@H](NC(=O)[C@@H](N)c2ccc(O)cc2)C(=O)N1C(=O)O</smiles>

Amoxicillin<smiles>CC(=O)Nc1ccc(O)cc1</smiles>

Paracetamol
Figure 1: Chemical structure of amoxicillin and paracetamol.

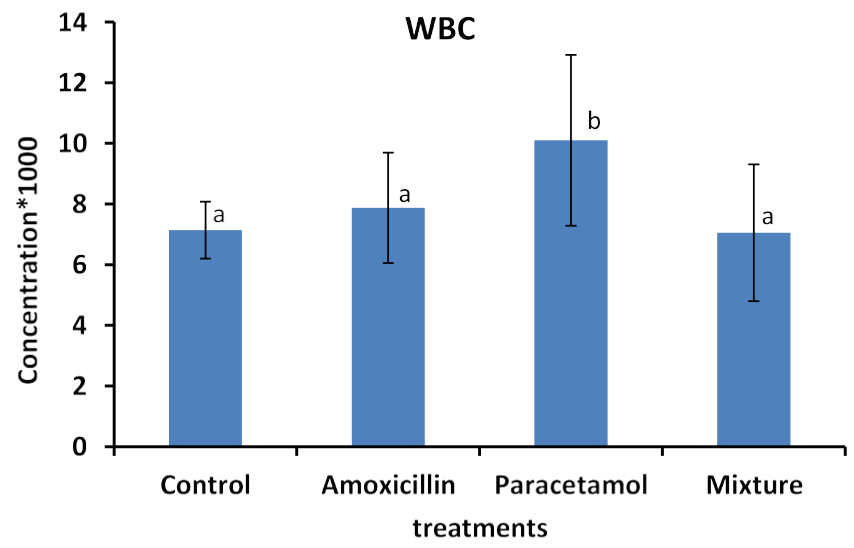

Figure 2: Concentrations of WBC in rabbit treated with Amoxicillin, Paracetamol, and their mixture. Error bars represent standard deviation. Columns have the same letter are not significantly different at $\mathrm{p} \leq 0.05$.

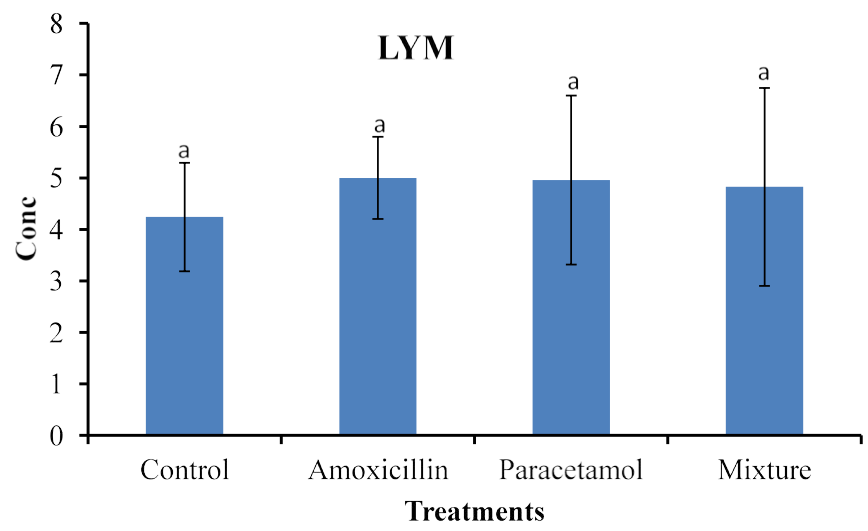

Figure 3: Concentrations of LYM in rabbit treated with Amoxicillin, Paracetamol, and Their mixture. Error bars represent standard deviation.

Columns have the same letter are not significantly different at $\mathrm{p} \leq 0.05$. 
Effects of the tested compounds on red blood cells are shown in Figure 4. Similarly, to the effects on lymph, increased level of red blood cells were observed in the treated rabbits but no significant differences were detected.

Effects of the tested compounds on the blood hemoglbine (HGB) are shown in Figure 5. Increased levels of HGB were observed in the treated rabbits. Satstical analysis detected significant difference among all treatment. this suggests an occurrence different biochemical reactions between HGB and the tested compounds.

Effects of the tested compounds on hematocreate (HCT) are shown in Figure 6. Similarly to the above effects, increased level of HCT were found in the treated rabbits but statistical differences were detected only in Amoxicillin and mixture treatments.

Effects of the tested compounds on the platlets (PLT) are shown in Figure 7. Similarly to the above effects, increased level of PLT were found in the treated rabbits. Statistical analysis detected significan differences.

The concentration of WBC and PLT in rabbits blood treated with Paracetamol were the highest among all treatments then Amoxicillin, whereas the concentration in rabbits treated with Mixture were lower than those of the control samples.

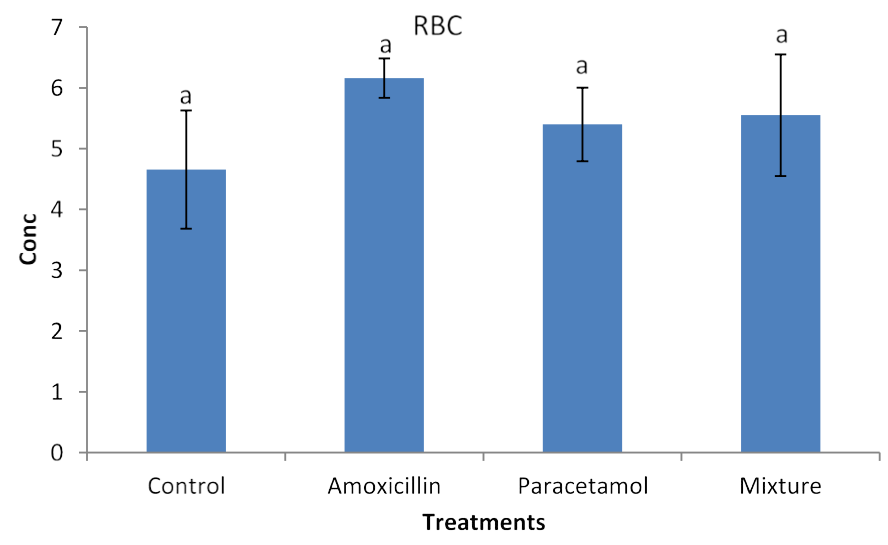

Figure 4: Concentrations of RBC in rabbit treated with Amoxicillin, Paracetamol, and Their mixture. Error bars represent standard deviation.

Columns have the same letter are not significantly different at $\mathrm{p} \leq 0.05$.

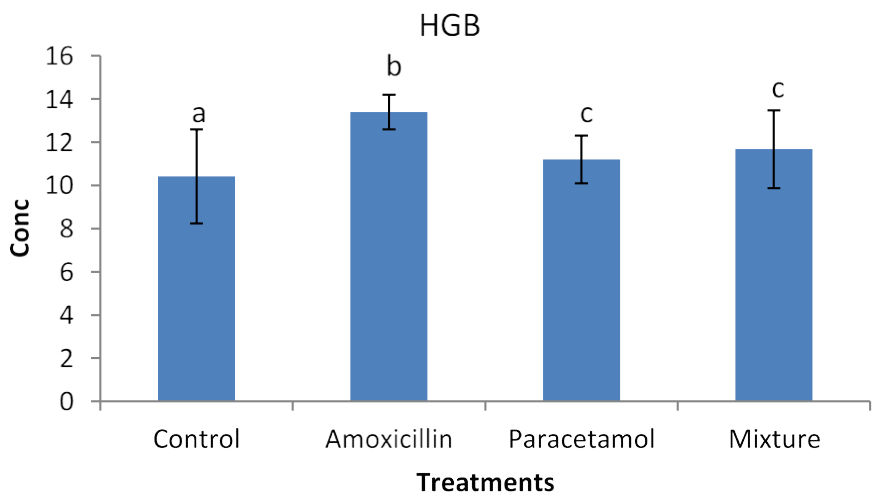

Figure 5: Concentrations of HGB in rabbit treated with Amoxicillin, Paracetamol, and Their mixture. Error bars represent standard deviation.

Columns have the same letter are not significantly different at $\mathrm{p} \leq 0.05$.

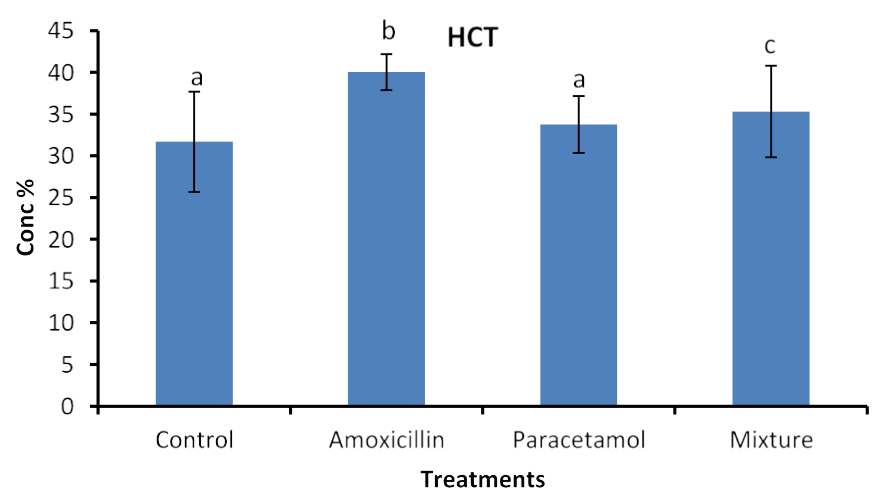

Figure 6: Concentrations of HCT in rabbit treated with Amoxicillin, Paracetamol, and Their mixture. Error bars represent standard deviation.

Columns have the same letter are not significantly different at $\mathrm{p} \leq 0.05$.

PLT

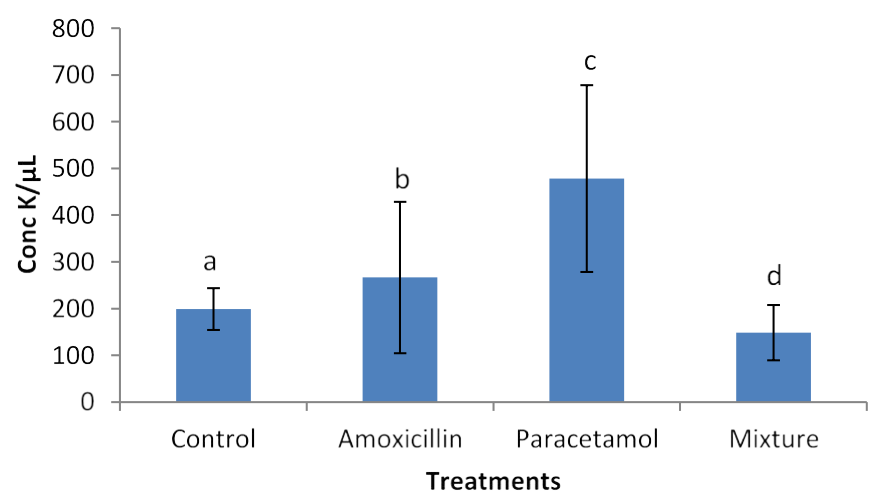

Figure 7: Concentrations of PLT in rabbit treated with Amoxicillin, Paracetamol, and Their mixture .Error bars represent standard deviation.

Columns have the same letter are not significantly different at $\mathrm{p} \leq 0.05$.

\section{Discussion}

Amoxicillin used as an antibiotic against bacteria [18] whereas paracetamol used as an analgesic for many diseases. There usage was associated with many complications as mentioned above. Furthermore, their chemical structure (Figure 1) shows the presence of highly water soluble groups such as $(\mathrm{OH} ; \mathrm{C}=\mathrm{O})$ which facilitate interaction and movement of the compounds in aqueous phase such as blood system. Additionally, the chemical structure includes phenyl ring which may enable covalent bonding with liver, kidney, and/or other tissue causing induced injury, in accordance with Lee et al. [19] who revealed similar phenomenon with other cases. Photo 1 show the oral gavage process of the tested compounds. The data in Figure 2, clearly demonstrates the effects of tested compounds on WBC. It can be seen that Amoxicillin and paracetamol increased WBC above that of the control, whereas the combination reduced the values. This suggests that treatments with Amoxicillin and paracetamol enhance the immune system to produce more WBC to defend the body from amoxicillin and paracetamol. Thus an increase of WBC cell would have occurred to enrich the body with the required level of WBC to insure health body. Our explanation agree with Díaz et al., [20] and Zarkesh et al., [16] who revealed the importance of WBC count on blood levels as long as the body exposed to bacterial infections and/or toxic chemicals $[21,22]$. 
On the other hand, the combination of the compounds did not increase the WBC. This suggests that the amoxicillin and paracetamol may antagonize each other in the combination accordingly no increase in WBC was observed (Figure 2). Furthermore, it can be suggested that application of the compounds in combination may provide a protection against possible injury. This suggestion is in agreement with [9] who revealed the activity of chiisanoside against liver injury induced by paracetamol in mice.

Nevertheless, the data in Figure 3, clearly shows increased levels of LYM but they remained insignificant with the control sample. This suggests that LYM does not involve in the immune system in the body. Similarly, no significant effects on RBC (Figure 4). This indicates that RBC is not involved in the immune system. On the other hands, HGB levels (Figure 5) are significantly increased in the treated rabbits. This suggests that HGB is involved in the defense systems throughout antibody antigen reactions. Our results are in accordance with El Menyiy et al. [23] and Biu et al. [24] who found that paracetamol significantly increased hemoglobin and platelet count as compared to the control group. An explanation of these results is that amoxicillin and paracetamol caused a dehydration process to the tested animal (data not shown) which may result in a hem concentration. Additionally, it can be suggested that paracetamol and/or amoxicillin can directly interact with blood system to further enhance the production of hemoglobin. Furthermore, it was reported that Paracetamol bond quinone reductase 2 in liver and kidney which modulated reactive oxygen species generation. This may further enhance the toxicity of paracetamol via quinone reductase 2 mediated superoxide production [13].

So far, lack of hemoglobin due to paracetamol or amoxicillin exposure may enhance the body to produce more hemoglobin to compensate the losses consequently an increase in hemoglobin level may be observed. Furthermore, the tested compound may cause hematotoxicity by restoring almost normal counts of the hematological parameters through oxidative stress. Our explanation agrees with Oyedeji et al. [25] who report oxidative stress in rat experiments. Influence of the tested compounds on HCT (Figure 6) showed significant increase in the treatment of Amoxicillin and mixture. The explanation on these results is similar to that given above for HGB. On the other hands significant increases in PLT levels (Figure 7) were observed in all treatments. An explanation of these results is that the tested compounds directly interact with PLT counts resulting in either activation as in amoxicillin and paracetamol or aggregation phenomenon as in mixture. Thus PLT tends to increase or decrease (Figure 7). Our explanation is in accordance with Siauw et al. [26] who provided evidence of the direct involvement of platelets with bacterial toxins.

\section{Mode of Interactions}

It can be suggested that amoxicillin and/or paracetamol be oxidized by dehydrogenase enzymes in human or animal body producing oxygen reactive species (ORS) as shown in Figure 8. Then these ORS react with blood systems resulting in elevation of HGB, HCT, and PLT in case of amoxicillin and WBC and PLT in case of paracetamol.

Moreover, the antagonistic effects of amoxicillin and paracetamol in the combination may result from the fact that both molecules have some similarity in the chemical structure such as phenyl ring, $\mathrm{C}=\mathrm{O}, \mathrm{NH} 2, \mathrm{CH} 3, \mathrm{OH}$. This similarity enhance hydrogen bonding, hydrophobic interactions and possible covalent bonding between both molecule resulting in a larger size molecule than parent ones (paracetamol, amoxicillin). This molecule can move freely in the human body and may not be able to be oxidized by dehydrogenases consequently no ORS were produced. Accordingly, WBC, HGB, LPT HCT contents remained in the acceptable range. This explanation is in accordance with El-Nahhal [27] who revealed hydrogen bonding and hydrophobic interactions between an organic molecules and acetylcholine esterase in human blood. Furthermore, previous reports $[28,29]$ revealed the solubility of similar organic molecules to each other in aqueous solution. Similar observations were recently reported with other cases [30-34]. Additionally, our results are in accordance with Mwafy and Afana who revealed changes in hematological parameters, serum iron and vitamin B12 levels in hospitalized Palestinian adult patients treated with amoxicillin.

\section{Conclusion}

The rational of this work emerged from the fact that paracetamol and amoxicillin are widely used pharmaceuticals and their hematological effects are poorly investigated. Elevation of WBC, HGB, LPT HCT levels in treated rabbits were significantly increased indicating high potential of hematological changes. Amoxicillin has

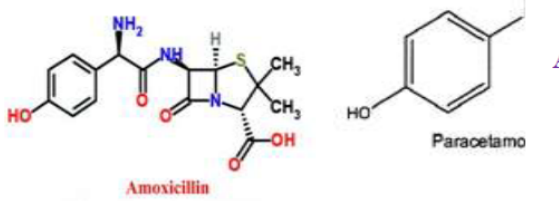

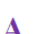

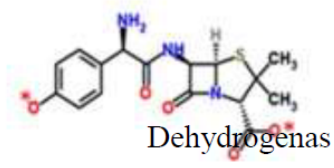

$$
\begin{aligned}
& { }_{\text {AGB }}^{\text {HGT }} \\
& \text { HCT } \\
& \text { PLT }
\end{aligned}
$$

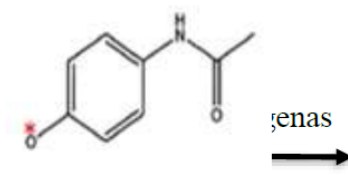

B

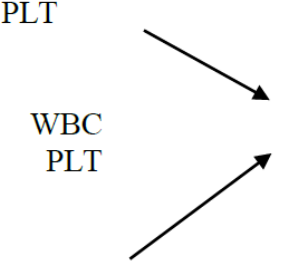

B

Figure 8: Possible mode of action of amoxicillin (A) and paracetamol (B) on blood systems after oxidation by dehydrogenase enzyme. 
a tremendous effect on blood components more that paracetamol has. Combination of both molecules did not produce significant changes on blood parameters indicating a possible protection to blood components. An interesting outcome of the study is that combination of both molecules can be a safe administration for this case.

\section{References}

1. Kaur SP, Rao R, Nanda S (2011) Amoxicillin: a broad spectrum antibiotic. Int J Pharm Pharm Sci 3: 30-37.

2. Tong DC, Rothwell BR (2000) Antibiotic prophylaxis in dentistry: a review and practice recommendations. The Journal of the American Dental Association 131: 366374. [crossref]

3. Abenavoli L, Libri E, Bosco D, Gallo D, Luzza F (2012) Drug-induced liver injury. Recenti Prog Med 103: 79-84. [crossref]

4. Nicoletti P, Aithal GP, Bjornsson ES, Andrade RJ, Sawle A, et al. (2017) Association of Liver Injury From Specific Drugs, or Groups of Drugs, With Polymorphisms in HLA and Other Genes in a Genome-Wide Association Study. Gastroenterology 152: 1078-1089. [crossref]

5. Elizalde-Velázquez A, Martínez-Rodríguez H, Galar-Martínez M, Dublán-García O, Islas-Flores H, et al. (2017) Effect of amoxicillin exposure on brain, gill, liver, and kidney of common carp (Cyprinus carpio): The role of amoxicilloic acid. Environ Toxicol 32: 1102-1120. [crossref]

6. Jóźwiak-Bebenista M, Nowak J Z (2014) Paracetamol: mechanism of action, applications and safety concern. Acta poloniae pharmaceutica 71: 11-23. [crossref]

7. Hinson JA, Roberts DW, James LP (2010) Mechanisms of acetaminopheninduced liver necrosis. Handb Exp Pharmacol 196: 369-405. [crossref]

8. James LP, McCullough SS, Knight TR, Jaeschke H, Hinson JA (2003) Acetaminophen toxicity in mice lacking NADPH oxidase activity: role of peroxynitrite formation and mitochondrial oxidant stress Free. Radic Res 37: 1289-97. [crossref]

9. Bian X, Wang S, Liu J, Zhao Y, Li H, et al. (2018) Hepatoprotective effect of chiisanoside against acetaminophen-induced acute liver injury in mice. Nat Prod Res 15: 1-4. [crossref]

10. deLemos AS, Ghabril M, Rockey DC, Gu J, Barnhart HX, et al. (2016) Drug-Induced Liver Injury Network (DILIN) Amoxicillin-Clavulanate-Induced Liver Injury. Dig Dis Sci 61: 2406-2416. [crossref]

11. Cao P, Sun J, Sullivan MA, Huang X, Wang H, et al. (2018) Angelica sinensis polysaccharide protects against acetaminophen-induced acute liver injury and cell death by suppressing oxidative stress and hepatic apoptosis in vivo and in vitro. Int $J$ Biol Macromol 111: 1133-1139. [crossref]

12. Bajt ML, Knight TR, Lemasters JJ, Jaeschke H (2004) Acetaminopheninduced oxidant stress and cell injury in cultured mouse hepatocytes: protection by $\mathrm{N}$-acetyl cysteine. Toxicol Sci 80: 343-9. [crossref]

13. Miettinen TP, Björklund $\mathrm{M}$ (2014) NQO2 is a reactive oxygen species generating offtarget for acetaminophen. Mol Pharm 11: 4395-404. [crossref]

14. Ghosh J, Das J, Manna P, Sil PC (2010) Acetaminophen induced renal injury via oxidative stress and TNF-alpha production: therapeutic potential of arjunolic acid. Toxicology 268: 8-18. [crossref]

15. Satav JG, Bhattacharya RK (1997) Respiratory functions in kidney mitochondria following paracetamol administration to young-adult and old rats. Indian J Med Res 105: 131-5. [crossref]

16. Zarkesh M, Sedaghat F, Heidarzadeh A, Tabrizi M, Bolooki-Moghadam K, et al. (2015) Diagnostic value of IL-6, CRP, WBC, and absolute neutrophil count to predict serious bacterial infection in febrile infants. Acta Med Iran 53: 408-11. [crossref]

17. El-Nahhal Y, Al_shareef A (2018) Effective biomarkers for successful management of sepsis. Trends in Medicine 18: 1-8.

18. Kim BJ, Kim JG (2013) Substitutions in penicillin-binding protein 1 in amoxicillinresistant Helicobacter pylori strains isolated from Korean patients. Gut Liver 7: 655660.

19. Lee J, Ji SC, Kim B, Yi S, Shin KH, et al. (2017) Exploration of Biomarkers for Amoxicillin/Clavulanate-Induced Liver Injury: Multi-Omics Approaches. Clin Transl Sci 10: 163-171. [crossref]
20. Díaz MG, García RP, Gamero DB, González-Tomé MI, Romero PC, et al. (2016) Lack of Accuracy of Biomarkers and Physical Examination to Detect Bacterial Infection in Febrile Infants. Pediatr Emerg Care 32: 664-668. [crossref]

21. El-Nahhal Y (2017) Risk Factors among Greenhouse Farmers in Gaza Strip Occupational Diseases and Environmental Medicine.

22. El-Nahhal Y, Lubbad R (2018) Acute and single repeated dose effects of low concentrations of chlorpyrifos, diuron, and their combination on chicken. Environmental Science and Pollution Research.

23. El Menyiy N, Al-Waili N, El Ghouizil A, Al-Waili W, Lyoussi B (2018) Evaluation of antiproteinuric and hepato-renal protective activities of propolis in paracetamol toxicity in rats. Nutrition Research and Practice 12: 535-540. [crossref]

24. Biu AA, Yusufu SD, Rabo JS (2009) Studies on the effects of aqueous leaf extracts of Neem (Azadirachta indica A juss) on haematological parameters in chicken. Afr Sci 10: 189-92.

25. Oyedeji KO, Bolarinwa A, Ojeniran SS (2013) Effect of paracetamol (acetaminophen) on haematological and reproductive parameters in male albino rats IOSR. J Pharm Biol Sci 4: 65-70.

26. Siauw C, Kobsar A, Dornieden C, Beyrich C, Schinke B, et al (2006) Group B streptococcus isolates from septic patients and healthy carriers differentially activate platelet signaling cascades. Thromb Haemost 95: 836-849. [crossref]

27. El-Nahhal Y (2018) Accidental Zinc Phosphide Poisoning among Population: A Case Report. Occupational Diseases and Environmental Medicine 6: 37-49.

28. El-Nahhal Y, Safi J (2004) Adsorption behavior of phenanthrene on organoclays under different salinity levels. Journal of Colloid and Interface Science 269: 265-273.

29. El-Nahhal Y, Safi, J (2004) Stability of an organo clay complex: effects of high concentrations of sodium chloride. Applied Clay Science 24: 129-136.

30. El-Nahhal Y, Raaed Lubbad, Mohammad R Al-Agha (2020) Toxicity Evaluation of Chlorpyrifos and Diuron below Maximum Residue Limits in Rabbits Toxicology and Environmental Health Sciences.

31. Matozzo V, Battistara M, Marisa I, Bertin V, Orsetti A (2016) Assessing the Effects of Amoxicillin on Antioxidant Enzyme Activities, Lipid Peroxidation and Protein Carbonyl Content in the Clam Ruditapes philippinarum and the Mussel Mytilus galloprovincialis Bull. Environ Contam Toxicol 97: 521-7. [crossref]

32. Mwafy SN, Afana WM (2018) Hematological parameters, serum iron and vitamin $\mathrm{B}_{12}$ levels in hospitalized Palestinian adult patients infected with Helicobacter pylori: a case-control study. Hematol Transfus Cell Ther 40: 160-165. [crossref]

33. Mihalaş E, Matricala L, Chelmuş A, Ghețu N, Petcu A, et al. (2016) The Role of Chronic Exposure to Amoxicillin/Clavulanic Acid on the Developmental Enamel Defects in Mice. Toxicol Pathol 44: 61-70. [crossref]

34. Seal P, Sikdar J, Roy A, Haldar R (2017) Acetaminophen interacts with Human Hemoglobin: Optical, Physical and Molecular modeling studies. J Biomol Struct Dyn 35: 1307-1321. [crossref]

\section{Citation:}

Abu Ebtehan NS, EL-Nahha Y (2021) Hematological Changes Associated with Amoxicillin, Paracetamol and Their Combinations on Rabbits Cells. Integr J Vet Biosci Volume 5(4): 1-5. 